\title{
Role of $\mathrm{Ar} / \mathrm{O}_{2}$ mixture on structural, compositional and optical properties of thin copper oxide films deposited by DC magnetron sputtering
}

\author{
N. Aghilizadeh ${ }^{1}$ A. H. Sari ${ }^{1}$ (D) D. Dorranian ${ }^{1}$
}

Received: 13 June 2017/ Accepted: 22 October 2017/Published online: 6 November 2017

(c) The Author(s) 2017. This article is an open access publication

\begin{abstract}
In this study, the effect of oxygen content on a thin copper oxide layer deposited on BK7 and steel substrates by DC magnetron sputtering were investigated. Argon as working gas with impurity of $99.9 \%$ and various oxygen ratios were used to sputter a pure $\mathrm{Cu}$ cathode target in a cylindrical geometry. The produced samples were analyzed by X-ray diffraction (XRD), energy-dispersive $\mathrm{X}$-ray (EDX), atomic force microscopy (AFM), and spectrophotometry techniques. The films thickness was measured by profilometer facility. The results show that by increasing oxygen content in the working gas the sputtering rate reduces. Moreover, the type of oxide phase $\left(\mathrm{Cu}_{2} \mathrm{O}\right.$ or $\mathrm{CuO})$ in the synthesized layer and consequently its optical properties dramatically depend on $\mathrm{Ar} / \mathrm{O}_{2}$ ratio in the working gas.
\end{abstract}

Keywords Copper oxide - Thin films · Magnetron sputtering $\cdot$ Optical properties

\section{Introduction}

Copper oxide as a thin film is an attractive material for various applications such as semiconductors, sensors, smart windows and photovoltaic devices [1-3]. Low-cost production abundant availability and nontoxic nature are some attractive features of this material. Thus, investigation of copper oxide films has both scientific and technological significance. It is important to know that the preparation

\section{A. H. Sari}

amirsari@gmail.com

1 Plasma Physics Research Center, Science and Research Branch, Islamic Azad University, Tehran, Iran technique can define the electrical and optical properties of the films [4]. Various methods such as evaporation [5-7], chemical vapor deposition [8], sputtering [9-13], thermal oxidation [14], sol-gel process [15], were used to produce the copper oxide film. The advantages of sputtering method are its flexibility, scalability, complexity of possible films, reproducibility, ability to work at low temperature, capability to deposit precisely controlled hetero structures, and simplicity of controlling the film composition, structure and morphology. The DC magnetron sputtering technique in the reactive mode is one of the ways to synthesize copper oxide thin films due to the excellent uniformity and controllability.

In this paper, the role of oxygen content added to the argon as working gas (WG) on the structural, compositional and optical properties of copper oxide film during magnetron sputtering process are reported. The use of a premixed WG $\left(\mathrm{Ar}+\mathrm{O}_{2}\right)$, cylindrical geometry of the magnetron sputtering system, simultaneous applying of two substrates (i.e., steel and transparent Bk7 glass), and investigation of morphology and thickness alongside other properties of the deposited films are some of the new features of the current research.

\section{Experimental details}

The polished AISI316 stainless steel and transparent Bk7 substrates $\left(1 \times 1 \mathrm{~cm}^{2}\right)$ were cleaned with acetone, ethyl alcohol, and de-ionized water in an ultrasonic bath, for 10 min each. DC magnetron sputtering system is schematically shown in Fig. 1. In this geometry, cathode (inner one, made from copper with impurity $\sim 99.99 \%$ and $3 \mathrm{~cm}$ diameter), and anode (outer one, made from aluminum) are two cylinders. 


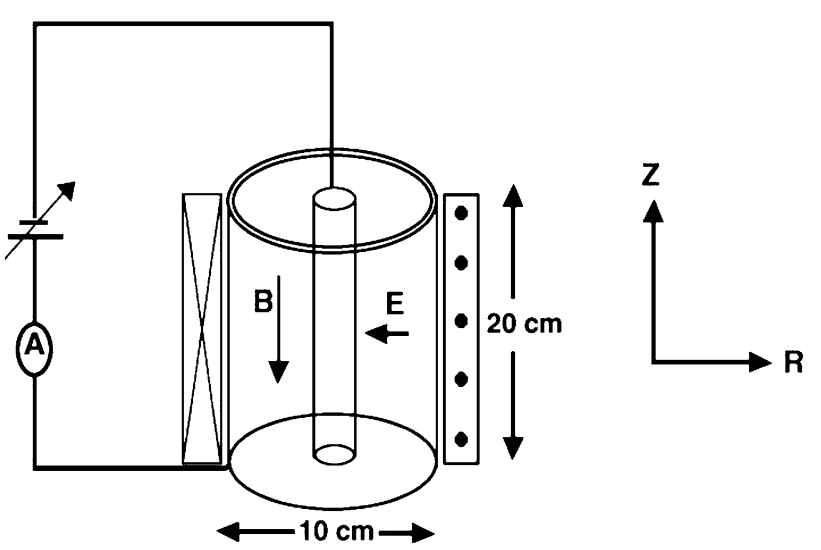

Fig. 1 The schematic view of the cylindrical magnetron sputtering system including electric and magnetic field directions (E and B)

WG in the deposition chamber was pure $\operatorname{Ar}(99.99 \%)$ or premixed $\mathrm{Ar}+\mathrm{O}_{2}$ with 5, 10, and $20 \%$ oxygen. Films were deposited under a fixed condition are presented in Table 1.

The sputtering process for BK7 and steel substrates were simultaneously performed for each sputtering regime. Transparent substrate (BK7) was used to obtain optical properties (i.e. transmission). The films thickness was measured after deposition process with a Surface Profile Meter, Bruker Dektak XT profilometer. To measure the standard error, the thickness of the deposited layer obtained at seven different points of the samples. The structure of the films were characterized by X-ray diffraction using a STOE model STADI MP diffractometer which uses $\mathrm{Cu} k \alpha$ $(\lambda=0.154 \mathrm{~nm})$ radiation. The surface morphologies were observed by Atomic Force Microscopy, Park Scientific Instrument, Auto probe CP. The optical transmission and reflection measurements in the range of $175-2500 \mathrm{~nm}$ were performed using a UV-Vis-NIR Spectrophotometer, Varian, Cary 500. Energy-dispersive X-ray (EDX) spectroscopy was carried out with AMETEK EDAX analyzer.

\section{Results and discussion}

\section{Film thickness}

The thickness of deposited layer and its evolution by increasing the oxygen content in the WG is shown Fig. 2. In the case of using $\mathrm{Ar}$ and $\mathrm{Ar}+5 \% \mathrm{O}_{2}$ no remarkable

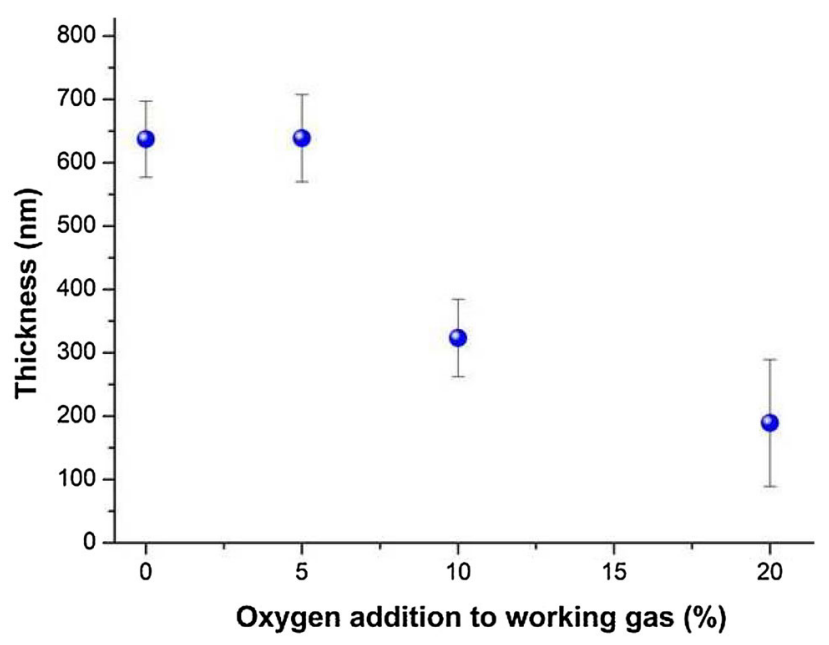

Fig. 2 Thickness versus oxygen content of WG in the sputtering process

difference is observed. Since the deposition time for all samples was constant, it can be concluded that $5 \%$ oxygen in the WG does not significantly change the sputtering yield and consequently the deposition rate. But there is a significant decrease (by a factor of two) in the thickness of sputtered layer for WGs with higher oxygen content (10 and 20\%). This reduction of thickness at higher oxygen content reflects the less efficiency of sputtering by oxygen plasma when compared with Ar plasma. It may also be possible that more oxygen in the WG causes the oxidation of the $\mathrm{Cu}$ target and oxidized target has lower sputtering rate.

\section{XRD and EDX results}

Figure 3 shows the XRD patterns of the samples before and after film deposition on steel substrates. The three peaks of the $\gamma$-Fe for the nickel-chrome steel is seen. When Ar is used as the WG of the sputtering process, the diffraction peaks at $2 \theta=43.50^{\circ}$ and $2 \theta=50.90^{\circ}$ enhance. Since the diffraction peaks of $\mathrm{Cu}(111)$ and $\mathrm{Cu}(200)$ are at the same position of $\gamma-\mathrm{Fe}$, this increase in the intensity is the evidence of the crystalline copper layer without any oxide phase. The injection of 5\% of oxygen in the WG leads to appearance of a small new peak at $2 \theta=37.06^{\circ}$. According to PDF card \#34-1354, this peak is related to the cubic phase of $\mathrm{Cu}_{2} \mathrm{O}$ (111). As seen in Fig. 3, this oxide phase at higher oxygen content is converted to the enriched oxide

Table 1 The condition of sputtering process

\begin{tabular}{llllll}
\hline Initial pressure (torr) & Working pressure (torr) & Deposition time (min) & Voltage (V) & Current (mA) & Magnetic field (G) \\
\hline $1 \times 10^{-5}$ & $1.5 \times 10^{-2}$ & 20 & 600 & 200 & 600 \\
\hline
\end{tabular}


Fig. 3 XRD patterns of samples on steel substrate before and after deposition at various oxygen content

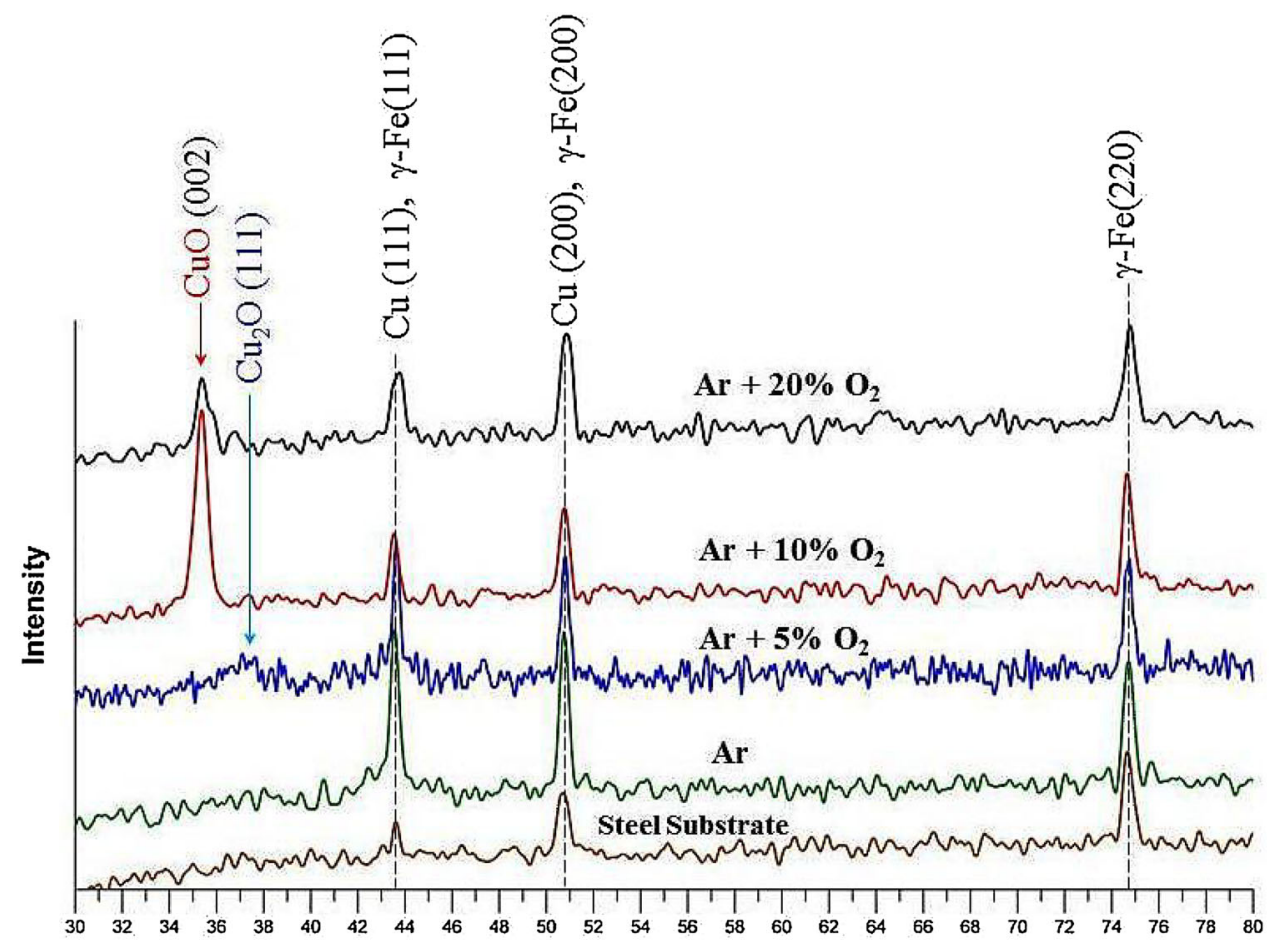

$2 \theta$ phase as $\mathrm{CuO}$. Using $\mathrm{Ar}+10 \% \mathrm{O}_{2}$ as $\mathrm{WG}$, at $2 \theta=35.38^{\circ}$ and according to PDF card \#45-937, $\mathrm{CuO}$ (002) has been formed. Using $\mathrm{Ar}+20 \% \mathrm{O}_{2}$ as WG, the same peak exists. According to the results of the thickness measurements, the decrease in the intensity of the $\mathrm{CuO}$ peaks at $\mathrm{Ar}+20 \% \mathrm{O}_{2}$ is connected to the oxidation of the $\mathrm{Cu}$ target or reduction of the sputtering rate and amount of the deposited layer.

For investigating the effect of substrate on phase composition of deposited layer, the XRD pattern of sample with BK7 substrate and $\mathrm{Ar}+5 \% \mathrm{O}_{2}$ as WG is demonstrated in

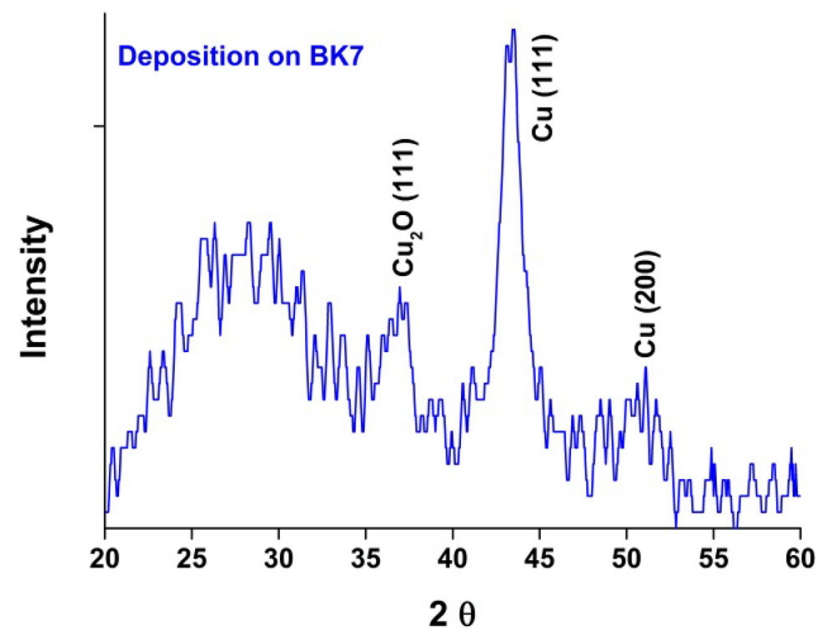

Fig. 4 XRD patterns of deposited layer on BK7 substrate for 5\% oxygen content in WG
Fig. 4. The hump for $2 \theta<35^{\circ}$ is related to the amorphous state of the substrate. Similar to steel substrate this result confirms the formation of $\mathrm{Cu}_{2} \mathrm{O}$ and $\mathrm{Cu}$ phases.

To obtain the atomic concentration of surface, the EDX analysis was performed. Table 1, shows the EDX results of two samples in a condition with 5 and $20 \%$ oxygen in the WG. According to Table 2, adding oxygen to WG, the deposited layer is saturated by oxygen. In the $20 \%$ case, this saturation is significant to expect the formation of a single phase of enriched oxygen (i.e. $\mathrm{CuO}$ ). This result is in agreement with XRD study.

Therefore, the controlling the phase composition in the deposited layer is possible by controlling the amount of $\mathrm{O}_{2}$ in the WG of the sputtering process.

\section{AFM results}

Figure 5 shows the AFM images of samples with or without oxygen in the WG of the sputtering process. The substrate for all images was steel. Figure 5.a represents the AFM result of the sputtered film when pure argon gas is utilized for plasma generation. Figure 5.a shows that multilevel configurations (submicron structures with $\sim 0.1 \mu \mathrm{m}$ in size consist of spherical nano-scale structures with $\sim 10-20 \mathrm{~nm}$ in radius) are observed on the surface. Adding 5\% oxygen gas in the WG of the sputtering process the structure of the resulted films significantly changes as seen in Fig. 5b. The first level (smaller nano-sized 
Table 2 EDX analysis of the films with various oxygen contents in the WG

\begin{tabular}{lll}
\hline Element & Concentration (at. \%) with $5 \% \mathrm{O}_{2}$ in WG & Concentration (at. \%) with $20 \% \mathrm{O}_{2}$ in WG \\
\hline $\mathrm{Cu}$ & 36.8 & 20.3 \\
$\mathrm{O}$ & 10.9 & 48.6 \\
\hline
\end{tabular}
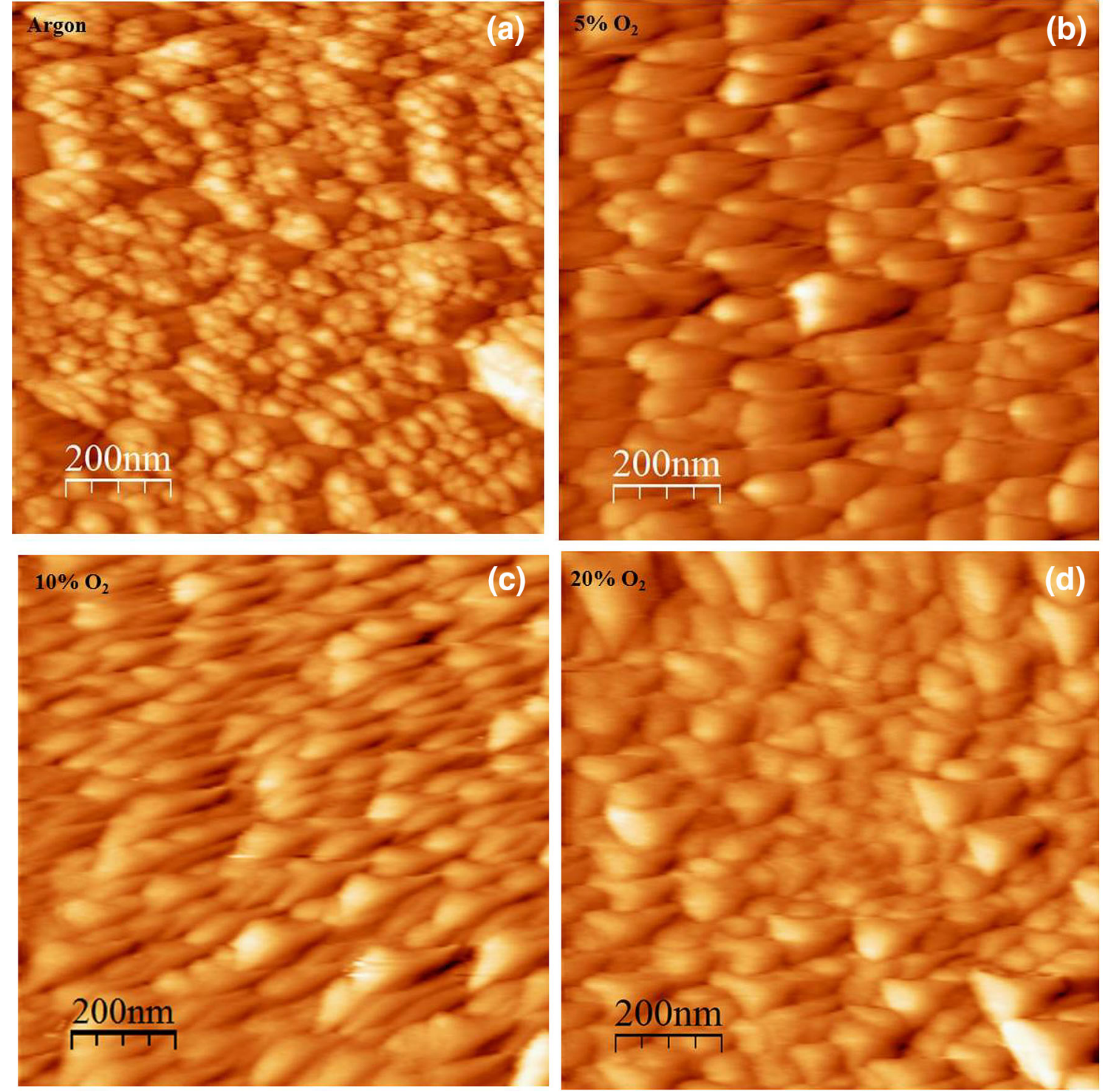

Fig. 5 The AFM images of sputtered film using different sputtering gas content a $\mathrm{Ar}$ gas, b $\mathrm{Ar}+5 \% \mathrm{O}_{2}, \mathbf{c ~} \mathrm{Ar}+10 \% \mathrm{O}_{2}, \mathbf{d ~ A r}+20 \% \mathrm{O}_{2}$

structures) disappears and the single enlarged grains are formed. Moreover, these grains become smaller at higher oxygen ratios (see Fig. 5b-d).

Although it is a difficult task to find a relationship between structures of the surface and amount of $\mathrm{O}_{2}$ in the $\mathrm{WG}$, but it can be connected to the creation of the new compositional phase $\left(\mathrm{Cu}, \mathrm{Cu}_{2} \mathrm{O}\right.$ or $\left.\mathrm{CuO}\right)$. Comparing Fig. $5 \mathrm{~b}$ with $\mathrm{c}$ and $\mathrm{d}$, it can be suggested that the decrease in the grain size at higher oxygen ratios (10 and 20\%) may be related to the smaller crystallites of $\mathrm{CuO}$ phase to $\mathrm{Cu}_{2} \mathrm{O}$ phase.

Therefore, the presence of $\mathrm{O}_{2}$ and its amount in the WG of the sputtering process not only change the composition of the sputtered film but also change the structure and morphology of the film. 
Fig. 6 Transmission versus wavelength for sputtered films with a 0 and $5 \%$ oxygen, and b 10 and $20 \%$ oxygen as WG
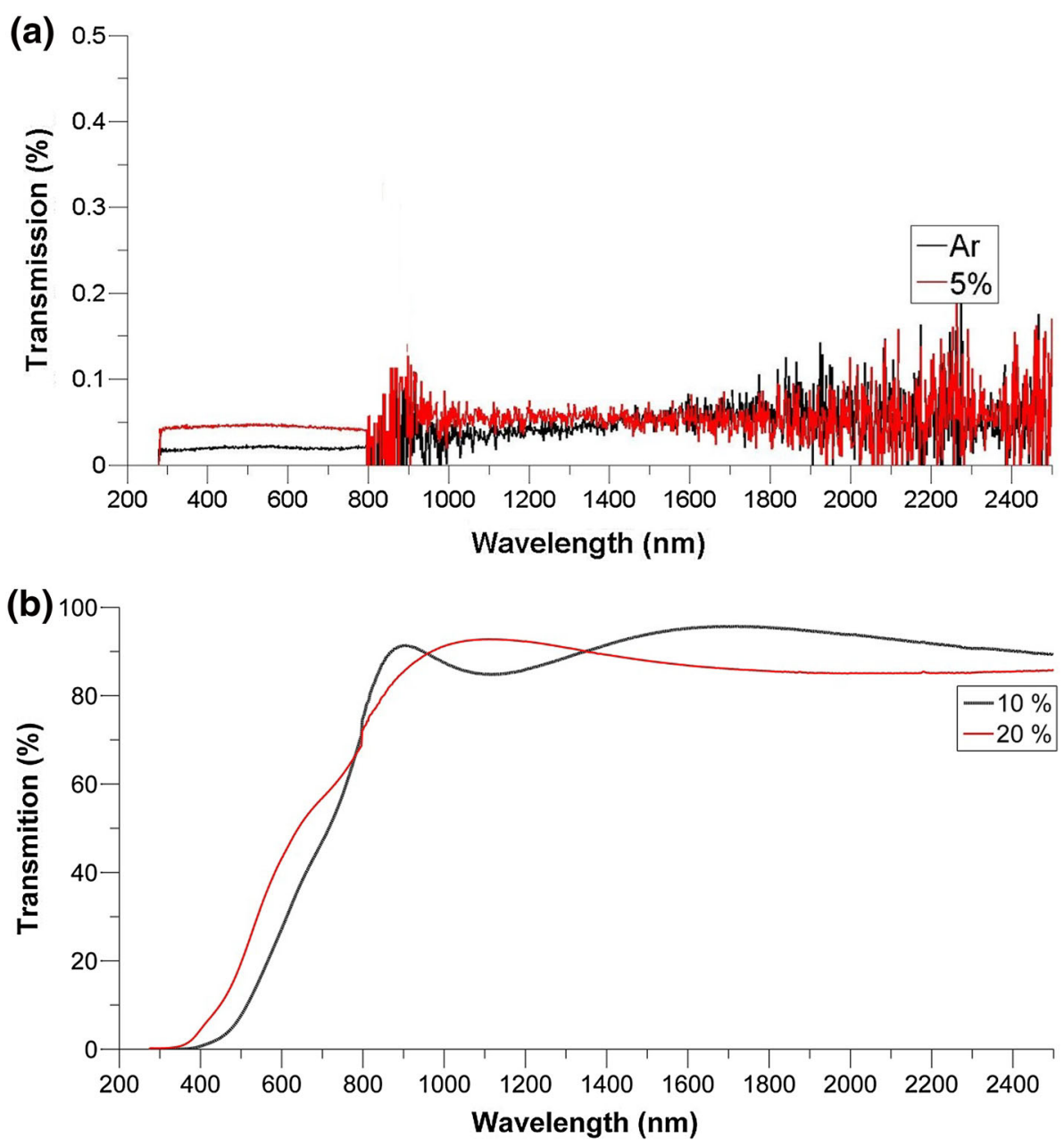

\section{Optical properties}

Figure $6 \mathrm{a}$ and $\mathrm{b}$ shows the optical transmission of the samples (with BK7 substrates) at wavelengths in the range of 200-2500 nm which were prepared under various $\mathrm{O}_{2}$ content. Sputtered thin films without oxygen or with $5 \% \mathrm{O}_{2}$ in the WG have a very low transmission (Fig. 6a. According to the XRD analysis, this is due to the presence of non-transparent $\mathrm{Cu}$ and $\mathrm{Cu}_{2} \mathrm{O}$ in the prepared films. With the increase in the amount of $\mathrm{O}_{2}$ in the WG, the transmission deposited films dramatically increase (Fig. 6b. To explain the optical behavior for the thin films sputtered with 10 and $20 \%$ oxygen in the WG, the optical band gap energies $\left(E_{g}\right)$ were calculated. A substantial drop in Fig. 6 near the absorption edge is related to the excitation of charge carriers over the optical band gap $[11,16]$.

The following formula shows that how incident photon energy is related to absorption coefficient $(\alpha)$ [16]

$\alpha h v=A\left(h v-E_{\mathrm{g}}\right)^{n}$,

in this relation $h$ is Planck's constant, $v$ is the frequency of light, $A$ is the edge width parameter, and value of $n$ depends on the type of transition [16]. Here the value of $n$ is 0.5 due to the direct allowed transition. By plotting $(\alpha h v)^{1 / n}$ ver$\operatorname{sus}(h v)$ a straight line is acquired and then optical band gap can be determined by extrapolation of the linear portion of the plots of $(\alpha h v)^{1 / n}$ versus $(h v)$ to $\alpha=0$. The transmittance $(T)$, reflectance $(R)$ and thickness of the film $(d)$ provide $\alpha$ by [17]:

$$
\alpha=-\frac{1}{d} \times \ln \left[\frac{T}{(1-R)^{2}}\right]
$$

Figure 7 shows the $(\alpha h v)^{2}$ versus $h v$ for the copper sputtered in the WG containing 10 and $20 \%$ oxygen. The optical band gap of 2.10 and $2.26 \mathrm{eV}$ obtained, respectively. The results indicate that by enhancing the oxygen content in the WG, the optical band gap increases. The higher band gap energy for deposited layer with $20 \%$ oxygen in WG is due to the greater transmittance of visible light as compared to the case of $10 \%$. In contrast to this, for 5 and $0 \%$ oxygen in the WG, since metallic $\mathrm{Cu}$ is dominant in these samples the explained method cannot be used to 


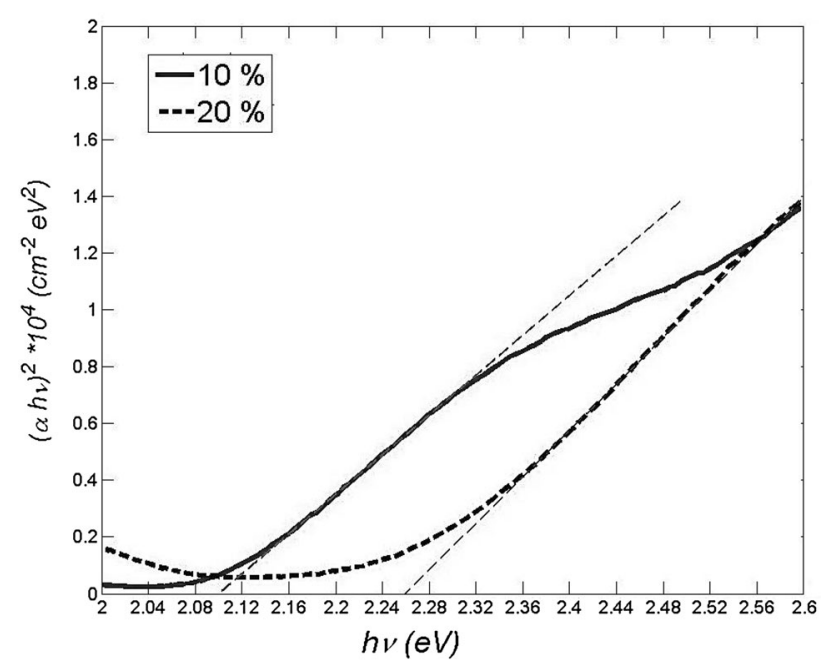

Fig. 7 Tauc plot [18] of samples for 10 and 20\% oxygen content of WG in the sputtering process

determine the optical band gap because metal does not have band gap structure.

\section{Conclusions}

Copper oxides $\left(\mathrm{Cu}_{2} \mathrm{O}\right.$ and $\left.\mathrm{CuO}\right)$ thin layers were produced by dc magnetron sputtering technique in a mixture of $\mathrm{Ar}$ and $\mathrm{O}_{2}$ gases and various oxygen contents. The increase in the amount of oxygen in the WG led to the decrease of the deposition rate and formation of the oxide phases from $\mathrm{Cu}_{2} \mathrm{O}$ to $\mathrm{CuO}$. The results showed that by increasing the amount of oxygen in the WG, the optical band gap enhanced. The optical band gap energies of 2.10 and $2.26 \mathrm{eV}$ obtained for 10 and $20 \%$ oxygen in the WG. Therefore, it can be concluded that by adjusting the amount of oxygen in the WG of the sputtering process the phase composition, optical behavior, and structure of the copper thin films can be controlled.

Open Access This article is distributed under the terms of the Creative Commons Attribution 4.0 International License (http://crea tivecommons.org/licenses/by/4.0/), which permits unrestricted use, distribution, and reproduction in any medium, provided you give appropriate credit to the original author(s) and the source, provide a link to the Creative Commons license, and indicate if changes were made.

\section{References}

1. Tao, M., Marson B., Rajeshwar K.: Next Generation Photovoltaics and Photoelectrochemistry Electrochemical Society. ECS Transactions. 11, 9 (2008)
2. Mittiga, A., Salza, E., Sarto, F., Tucci, M., Vasanthi, R.: Heterojunction solar cell with $2 \%$ efficiency based on a $\mathrm{Cu} 2 \mathrm{O}$ substrate. Appl. Phys. Lett. 88, 163502 (2006)

3. Akimoto, K., Ishizuka, S., Yanagita, M., Nawa, Y., Paul, G.K., Sakurai, T.: Thin film deposition of $\mathrm{Cu} 2 \mathrm{O}$ and application for solar cells. Sol. Energy. 80, 715 (2006)

4. Derin, H., Kantarli, K.: Optical characterization of thin thermal oxide films on copper by ellipsometry. Appl. Phys. A. 75, 391 (2002)

5. Balamurugan, B., Mehta, B.R.: Optical and structural properties of nanocrystalline copper oxide thin films prepared by activated reactive evaporation. Thin Solid Films 396, 90 (2001)

6. Al-Kuhaili, M.F.: Characterization of copper oxide thin films deposited by the thermal evaporation of cuprous oxide $(\mathrm{Cu} 2 \mathrm{O})$. Vacuum. 82, 623 (2008)

7. Tounsi, N., Barhoumi, A., Chaffar Akkari, F., Kanzari, M., Guermazi, H., Guermazi, S.: Structural and optical characterization of copper oxide composite thin films elaborated by GLAD technique. Vacuum. 121, 9 (2015)

8. Maruyama, T.: Copper oxide thin films prepared by chemical vapor deposition from copper dipivaloylmethanate. Solar Energy Materials and Solar Cells. 56, 85 (1998)

9. Lee, H.H., Lee, C., Kuo, Y.L., Yen, Y.W.: A novel two-step MOCVD for producing thin copper films with a mixture of ethyl alcohol and water as the additive. Thin Solid Films. 498, 43 (2006)

10. Reddy, A.S., Uthanna, S., Reddy, P.S.: Properties of dc magnetron sputtered $\mathrm{Cu} 2 \mathrm{O}$ films prepared at different sputtering pressures. Appl. Surf. Sci. 253, 5287 (2007)

11. Reddy, A.S., Park, H.H., Reddy, V.S., Reddy, K.V.S., Sarma, N.S., Kaleemulla, S., Uthanna, S., Reddy, P.S.: Effect of sputtering power on the physical properties of dc magnetron sputtered copper oxide thin films. Mater. Chem. Phys. 110, 397 (2008)

12. Reddy, A.S., Reddy, P.S., Uthanna, S., Rao, G.V., Klein, A.: Effect of substrate temperature on the physical properties of dc magnetron sputtered Cu2O films. Phys. Status. Solidi. A. 203, 844 (2006)

13. Reddy, A.S., Rao, G.V., Uthanna, S., Reddy, P.S.: Influence of substrate bias voltage on the properties of magnetron sputtered Cu2O films. Phys. B. 370, 29 (2005)

14. Hsieh, J.H., Kuo, P.W., Peng, K.C., Liu, S.J., Hsueh, J.D., Chang, S.C.: Opto-electronic properties of sputter-deposited $\mathrm{Cu} 2 \mathrm{O}$ films treated with rapid thermal annealing. Thin Solid Films. 516, 5449 (2008)

15. Musa, A.O., Akomolafe, T., Carter, M.J.: Production of cuprous oxide, a solar cell material, by thermal oxidation and a study of its physical and electrical properties. Sol. Energy. Mater. Sol. Cells. 51, 305 (1998)

16. Ray, S.C.: Preparation of copper oxide thin film by the sol-gellike dip technique and study of their structural and optical properties. Sol. Energy Mater. Sol. Cells. 68, 307 (2001)

17. Fox, M.: Optical properties of solids. Oxford University Press, New York (2001)

18. Tauc, J.: Optical properties and electronic structure of amorphous Ge and Si. Mater. Res. Bull. 3(1), 37-46 (1968) 